\title{
COMPARATIVE STUDY OF MOORE AND MEALY MACHINE MODELS ADAPTATION IN BLACK SOAP PRODUCTION
}

\author{
S. A. Akinboro ${ }^{1,}$, A. Omotosho' ${ }^{2}$, J. A. Adeyiga ${ }^{3}$ and E. Effiom ${ }^{4}$

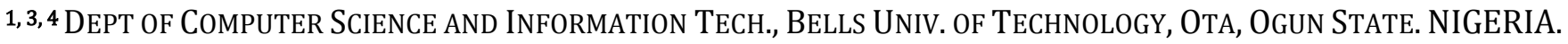 \\ 2 DEPARTMENT OF COMPUTER SCIENCE, LANDMARK UNIVERSITY, OMU ARAN, KWARA STATE. NIGERIA \\ E-mail addresses:1akinboro2002@yahoo.com, 2bayotosho@gmail.com, 3jadeyiga@yahoo.com, \\ 4eme_effiom@yahoo.com
}

\begin{abstract}
Information and Communications Technology has influenced the need for automated machines that can carry out important production procedures and, automata models are among the computational models used in design and construction of industrial processes. The production process of the popular African Black Soap (ABS), which is widely used for the alleviation of various skin ailments among other uses, is still mostly done manually. In this paper, an automata model was developed for ABS manufacturing process using Moore and Mealy Finite State Machines. Simulation of standard input of raw materials into the machine was achieved using Input-Output methodology with pseudo random number generated input data. The output of this methodology served as the actual fractional contents of the raw ingredients fed into the Moore and Mealy machine. The automata models were simulated for ten runs using application developed with Microsoft Visual C\#. The performance of each machine was assessed in order to determine, the most efficient of the machines using execution time as parameter. The simulation results showed that the Mealy Machine is faster than the Moore Machine as evident by the time overhead of over 3 hrs in the production time process of ABS.
\end{abstract}

Keywords: Finite state machines, Black soap, Moore machine, Mealy machine.

\section{INTRODUCTION}

African Black Soap (ABS) is a traditional, pure vegetable soap which was originated in Africa. Its natural black colour reflects ashes which is its key ingredients. The soap is usually made from readily available and cost effective materials and it is suitable for use in the home for especially for cleaning, bathing and washing. ABS enjoys a reputation for improving or eliminating uneven skin tone, razor bumps caused by ingrown hairs and skin rashes. In Africa, because of its popularity traditional black soaps are known with different names in different regions of the continent. For instance, in the some western part of Africa, black soap is known as Anago soap, Alata Simena in Ghana, Ose-dudu among the Yorubas in Nigeria [1].Largely ABS production in West Africa today, is still done manually which demands hours of stirring by hand and in the local soap industry, production involves strenuous human efforts. The mixing of ingredients is done with a stick or wooden ladle and this requires a lot of energy and time input by the soap producer. Most times, the final product is usually not uniformly mixed due to fatigue usually suffered by the operator [2]. ABS has high economic value, and its production process enables recycling of agro-wastes such as cocoa pod husks, Palm-bunch waste, sorghum chaff and groundnut shells which were usually disposed and seen as valueless. Hence, there is an impending need to automate this production process. Also, unlike other soaps which are made from oils and chemicals, ABS is made from oils and agro-waste ashes [3], these agrowastes used in ABS, make it a natural source of vitamin A, $\mathrm{E}$ and iron which are good for skin care [4]. Owing to importance and possible derivable benefits accrued in the $\mathrm{ABS}$, the importance of a machine that can carry out the production procedures effectively cannot be over emphasized. This paper presents a computational model for ABS manufacturing process.

\section{RELATED WORKS}

The production of ABS involves eight distinct stages [5]: Extraction- The Process involves the extraction palm oil, Burning- burning the plantain skins and cocoa pods in fire until it turns to ashes, Mixing - ashes gotten from the burning stage is mixed with water, Leaching - the ash 
solution is then leached to remove excess water, Boilingthe dilute ash solution is boiled to increase the concentration. Cooking- This process involves cooking the ash solution with the addition of palm kernel, Adding - extra ingredients are added to the soap mix if necessary. If the ingredients were sufficient, the soap is being cooled in the cooling stage, and Cooling- the cooling of hot soap for about two weeks in order to solidify before it is ready for use. However, black soap making process is similar to the general soap making process because in both processes, the lye is being cooked with oil to obtain the soap. In black soap, the burning, mixing and leaching of agricultural wastes is carried out in other to obtained one of the base ingredient which is the Sodium hydorzide $(\mathrm{NaOH}$, also known as lye).The lye obtained here is of a natural origin, while the lye used in general soap making is chemical based.

Some of the existing Moore and Mealy models for various manufacturing processes were reviewed in order to identify the research description. Finite state machine factors and methods were also considered. A few of these were discussed as follows:

Ibrahim, et al [6] presented a model of Sokoto cement production process using a finite automaton scheme and also carried out an analysis of the model. This work adopts the method of the deterministic finite automata to construct the production model by using the production processes to denote different states linked by different transition functions. The preliminary results indicate that from the model of the cement production processes the transition table obtained can be used to interpret the order of the cement production process and a gateway towards studying more detailed transition matrix in terms of algebraic theoretic properties.

Varkey, et al [7] proposed and implemented a Multi Select Smart Vending Machine using the mealy model of finite state machine. The results indicate an increase in efficiency, resource utilization and accuracy. The model exhibited the delay of 7.890 ns and a calculated maximum operating frequency of $126.744 \mathrm{MHz}$. The model can be applied in real life development of a multi select smart vending machine. Sitaula, et al [8], proposed a finite state machine approach to find the semantic similarity of two sentences in the field of natural language processing. They designed an algorithm for Nepali texts which was implemented and algorithm gave recall of $90.15 \%$. The approach used was able to find the semantic similarity of two sentences and determine coherence in sentences.

Verma and Karambir [9] purported a Finite automata model for component testing. They developed a testing technique that was simple, effective, and less complex and could do a thorough testing of an application as well as detection of errors. The model can be applied in error detection for component based software applications. Klimovich and Solov'ev [10], proposed a method of transforming a mealy finite state machine into a Moore finite state machine by splitting of internal states. Experiment results have shown that transforming Mealy FSM into Moore FSM increases the number of internal states, by a factor of 1.96 and increases the number of transitions by a factor of 2.05.This method is applied in engineering design. Zainuddin, et al [11], proposed a vending machine for steaming frozen food using conceptual modelling. The model reduced the amount of hardware required and the number of states needed. It also transforms the deliverables into visualized form for easy comprehension. This model can be applied in real life vending machines.

In [12] a methodology to model finite state machines using Class and State chart UML diagrams was presented. This method allows the reduction in amount of manual programming and increases the quality of resulting code. It is Applicable in modelling and execution of object oriented applications in real life scenarios. In [13], a design for a traffic light control at a level crossing of a railway and a road using the finite state machine methodology or model was proposed. The Moore machine model was used for controlling the traffic lamp. The design is simplified and is considered quite effective in traffic control if applied in a real life scenario. The design can be applied in real life traffic control at level crossing of railway and road. All these review established the fact that automata models are among the computational models used in design and construction of industrial processes. These models have demonstrated good results in other systems which could make them relevant in the design of ABS production process as well.

\section{MATERIAL AND METHODS}

The conceptual model in Figure1 illustrates the process of manufacturing black soap. Cocoa pods are sundried and then roasted in a kettle or pot at an even, constant temperature, which is necessary to ensure and enhance colour, texture and smell. The water and oil are added to the mixture and stored for at least a day to solidify. The above processes can be described in distinct stages: extraction, burning, mixing, leaching, boiling, cooking, adding, and cooling. This conceptual model was designed by studying the manually process of black soap making. It visually represents how the black soap is made indicating its inputs, and corresponding outputs, the processes or equipment, and the final output which is the African black soap. 


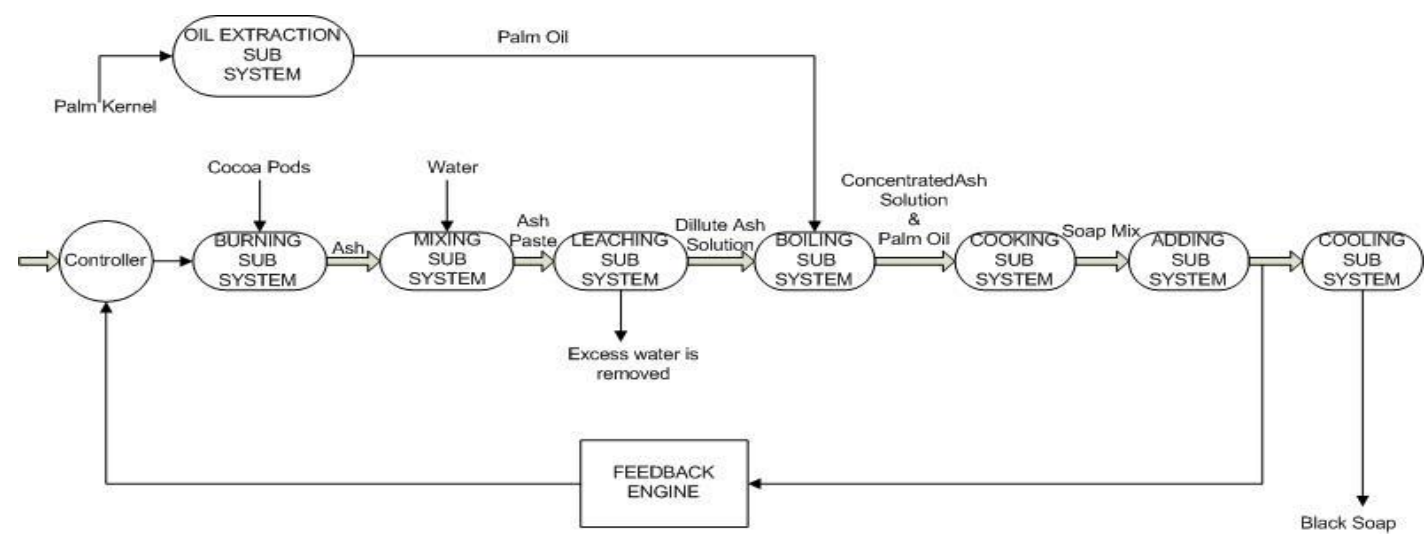

Figure 1: The Conceptual model of the black soap manufacturing process

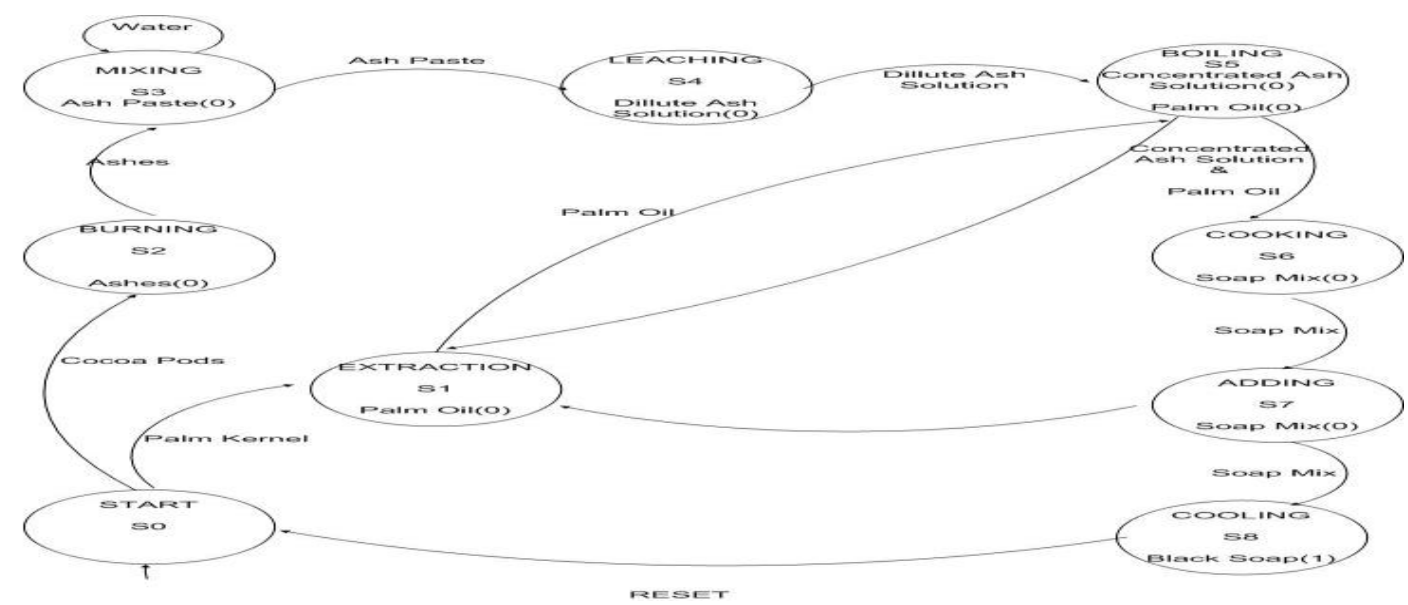

Figure 2: The Moore machine model for black soap manufacturing process

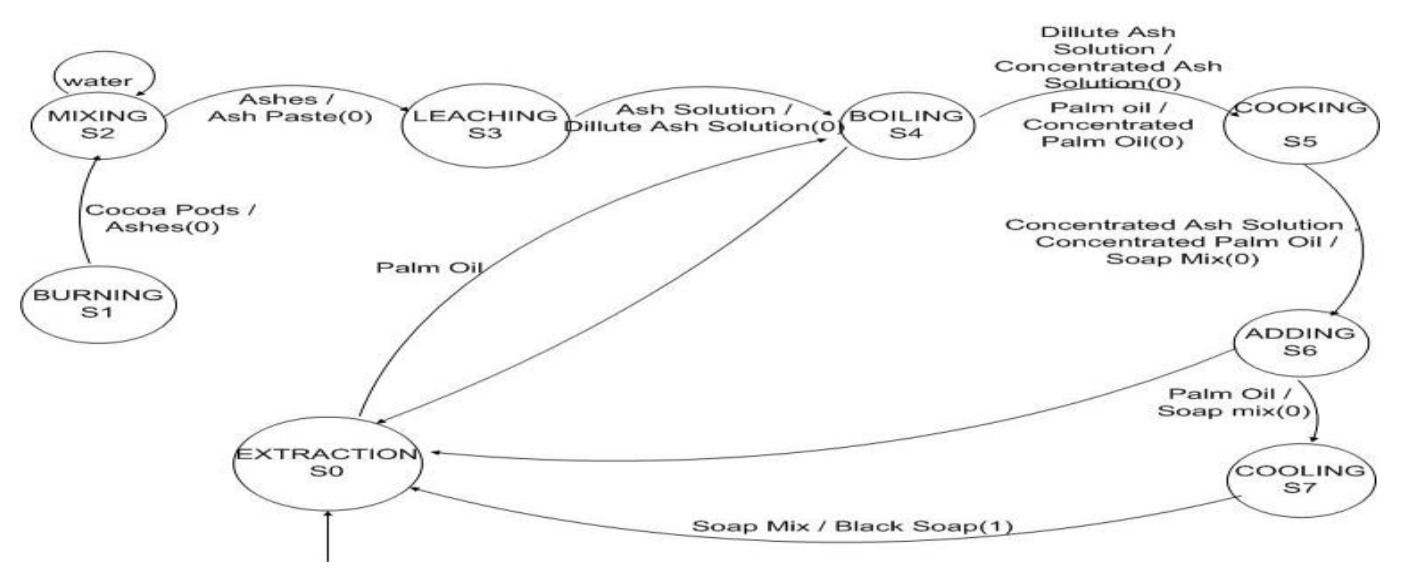

Figure 3: The Mealy machine model for the black soap manufacturing process

\subsection{Mealy and Moore Computational Modeling of the Black Soap Making Process}

The purpose of modeling is to study the process using the Moore and Mealy machine and assess the performance of each thereby determining the most effective machine for the process. The development of a computational model would specify a framework to support the evaluation of the efficiency in production.

The transition table in Table 1 was derived from the Moore machine model in Figure 2. It is based on the assumption that Cocoa Pods (A), palm kernel (B) and water are used as inputs (C) and corresponding outputs
(Z) are obtained for each state in the Moore machine. The next state $\operatorname{logic}(\mathrm{S})$ tells the next state the automaton in Figure 2 goes to depending in its previous state.

From the Mealy machine model on Figure 3, the transition table in Table 2 was derived. It is also based on the assumption that Cocoa Pods, palm kernel and water are used as inputs (A, B and C respectively) and corresponding outputs (Z) were obtained for each state in the Moore machine as well as the next state $\operatorname{logic}(\mathrm{S})$ which tells the next state the automata in figure 3 goes to depending in its previous state. 
Table 1: The transition table for the Moore machine model

\begin{tabular}{llllll}
\hline Present State(S) & A & B & C & Next State(S') & Output Z \\
Start & 0 & 0 & 0 & Extraction & 0 \\
\hline Start & 0 & 0 & 1 & Burning & 0 \\
Extraction & 0 & 1 & 0 & Boiling & 0 \\
Burning & 1 & 0 & 0 & Mixing & 0 \\
Mixing & 1 & 0 & 1 & Mixing & 0 \\
& 1 & 1 & 0 & Leaching & 0 \\
Leaching & 1 & 1 & 1 & Boiling & 0 \\
Boiling & 0 & 0 & 0 & Extraction & 0 \\
& 0 & 0 & 1 & Cooking & 0 \\
Cooking & 0 & 1 & 0 & Adding & 0 \\
Adding & 0 & 1 & 1 & Extraction & 0 \\
& 1 & 0 & 0 & Cooling & 0 \\
Cooling & 1 & 0 & 1 & Start & 1 \\
\hline
\end{tabular}

Table 2: The transition table for the Mealy Machine model

\begin{tabular}{|c|c|c|c|c|}
\hline Present State(S) & $\mathrm{A}$ & $\mathrm{B}$ & Inputs/ output $\mathrm{C}$ & Next State(S') \\
\hline \multirow[t]{2}{*}{ Extraction } & 0 & 0 & 0,0 & Boiling \\
\hline & 0 & 0 & 1,0 & Adding \\
\hline Burning & 0 & 1 & 0,0 & Mixing \\
\hline \multirow[t]{2}{*}{ Mixing } & 0 & 1 & 1,0 & Mixing \\
\hline & 1 & 0 & 0,0 & Leaching \\
\hline Leaching & 1 & 0 & 1,0 & Boiling \\
\hline \multirow[t]{2}{*}{ Boiling } & 1 & 1 & 0,0 & Extraction \\
\hline & 1 & 1 & 1,0 & Cooking \\
\hline Cooking & 0 & 0 & 0,0 & Adding \\
\hline \multirow[t]{2}{*}{ Adding } & 0 & 0 & 1,0 & Extraction \\
\hline & 0 & 1 & 0,0 & Cooling \\
\hline Cooling & 0 & 1 & 1,1 & Extraction \\
\hline
\end{tabular}

Table3: The input-output technology matrix

\begin{tabular}{cccc|cc}
\hline \multicolumn{3}{c|}{ Outputs } & & \multicolumn{3}{c}{ B } \\
\hline & 1 & 2 & 3 & $\begin{array}{c}\text { Final } \\
\text { Input }\end{array}$ & $\begin{array}{c}\text { Total } \\
\text { Input }\end{array}$ \\
\hline Oil 1 & $\alpha_{1} \mathrm{~m}_{1}$ & $\alpha_{2} \mathrm{~m}_{2}$ & $\alpha_{3} \mathrm{~m}_{3}$ & $\mathrm{M}_{\text {oil }}$ & $\alpha_{\mathrm{m}}$ \\
Ash 2 & $\beta_{1} \mathrm{~m}_{1}$ & $\beta_{2} \mathrm{~m}_{2}$ & $\beta_{3} \mathrm{~m}_{3}$ & $\mathrm{M}_{\text {ash }}$ & $\beta_{\mathrm{m}}$ \\
Water 3 & $\gamma_{1} \mathrm{~m}_{1}$ & $\gamma_{2} \mathrm{~m}_{2}$ & $\gamma_{3} \mathrm{~m}_{3}$ & $\mathrm{M}_{\text {water }}$ & $\gamma_{\mathrm{m}}$ \\
Added & $\mu_{1}$ & $\mu_{2}$ & $\mu_{3}$ & 0 & 0 \\
Products & & & & & 0 \\
Total output & $\alpha_{\mathrm{m}}$ & $\beta_{\mathrm{m}}$ & $\gamma_{\mathrm{m}}$ & 0 & 0 \\
\hline
\end{tabular}

Where: $m_{1}$ is the Mass of output $1, m_{2}$ is the Mass of output $2, \mathrm{~m}_{3}$ is the Mass of output $3, \alpha_{1}$ is the oil fraction in output $1, \alpha_{2}$ is the oil fraction in output $2, \alpha_{3}$ is the oil fraction in output $3, \beta_{1}$ is the Ash fraction in output $1, \beta_{2}$ is the Ash fraction in output $2, \beta_{3}$ is the Ash fraction in output $3, \gamma_{1}$ is the Water fraction in output $1, \gamma_{2}$ is the Water fraction in output $2, \gamma_{3}$ is the Water fraction in output $3, \mu_{1}$ is the Total ingredient in first feedback return, $\mu_{2}$ is the Total ingredient in second feedback return, $\mu_{3}$ is the Total ingredient in third final feedback return.

\subsection{Mathematical Modeling of the Black Soap Manufacturing Process Using Input-Output Methodology}

The mathematical equation was created using the input output methodology. It illustrates the production process of black soap based on the assumption that the machine performs quality control of the final product by controlling the inputs in order to obtain the desired output. First, the Technology Matrix in Table 4 was obtained which carries information on the inputs and outputs of the system.

The matrix of technical coefficients is obtained which gives the actual fractional contents of ingredients in the system shown in equation 1 :

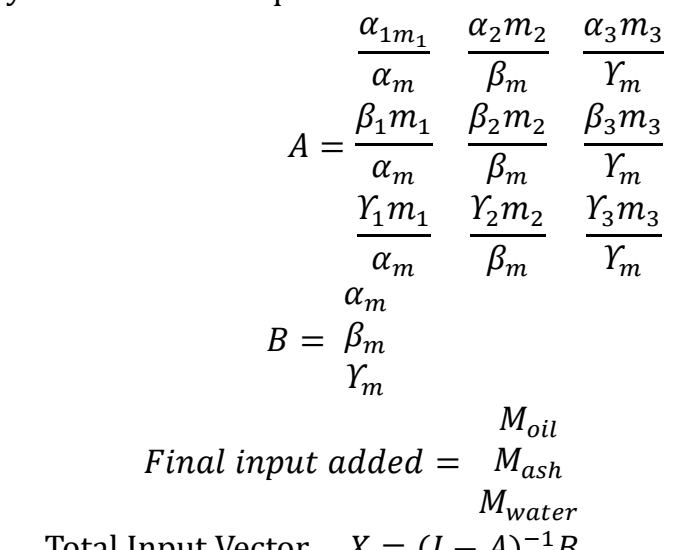

Total Input Vector, $X=(I-A)^{-1} B$

Where: $I$ is the identity matrix, $X$ is the input vector (i.e. the vector representing the total input to be added) and $\mathrm{A}$ is the coefficient matrix. Therefore the fractional mass of the ingredients (ash, oil and water) added to the system in each production runs is given as:

$$
\begin{aligned}
& \alpha_{1} m_{1}+\alpha_{2} m_{2}+\alpha_{3} m_{3}+M_{\text {oil }}=\alpha_{m} \\
& \beta_{1} m_{1}+\beta_{2} m_{2}+\beta_{3} m_{3}+M_{\text {ash }}=\beta_{m} \\
& \Upsilon_{1} m_{1}+\Upsilon_{2} m_{2}+\Upsilon_{3} m_{3}+M_{\text {water }}=\Upsilon_{m}
\end{aligned}
$$

Random numbers generator inMatlab7.0 was used to generate input values for each variable in the mathematical model and substituted into the matrices in the model in order to obtain the actual values of the fractional masses of ingredients. The choice of a pseudo random numbers generator was made because the quantities of the raw inputs into the machine cannot be fixed or pre-defined but rather random and we cannot ascertain their input ratio. However, these random values were standardized throughout the usage of the input output mathematical model. These computed values were used as inputs for the simulation. Random numbers were also generated for the estimated time of each production process during simulation. The overall system was implemented using Microsoft Visual C\#. 


\section{SIMULATION OF THE MODELS}

Pseudo-random numbers were substituted into the matrix of technical coefficients (equation1) because these random numbers represent Input data to mathematical model, in order to solve the derived equation, they are substituted into the equation and the results obtained are shown in table 5 .

The random numbers generated were substituted into equation 4to obtain the fractional masses of ingredients (ash, oil and water) as shown in table 6. These values which are the fractional masses of ingredients (Ash, oil and water) are further used as inputs during simulation. This work is concerned with the performance of the Moore and Mealy machine using execution time as parameter, in order to carry out the simulation, the masses of each ingredients used is required. These masses could vary between individuals, so the inputoutput methodology is used to generate the masses of each ingredient for use as input during simulation. Random numbers were generated for the estimated time of each process using Matlab7.0 for 10 runs as shown in Table 7. Random numbers are used here because in determining the most efficient machine for the process, the simulation would be carried out for several runs, and final execution time values would be assessed to determine a pattern in the result. The use of random numbers here helps avoid repetition of actual process times for each of the runs.

\section{RESULTS AND DISCUSSION}

This work focuses on knowing which machine is faster in delivering of its outputs using any input set. The simulation steps were repeated for consecutive values from Table 6 and Table 7. These iterative steps are demonstrated in Figure 4a to Figure 4j which shows the result of the first set of inputs in Figure 4j. The other set of inputs were processed in a similar manner. Table 8 shows a comprehensive summary of the processing time of the two automata models using the designed methodology. The simulation results indicate that the Mealy Machine is faster than the Moore machine in delivering its outputs for the ABS process. Mealy Machine took an estimated running time of $11 \mathrm{hrs} 44 \mathrm{mins}$ compared to $8 \mathrm{hrs} 27 \mathrm{mins} 44 \mathrm{secs}$ taken by Moore Machine for the ten simulations run.

Table 5: Results obtained from matrix of technical coefficients

\begin{tabular}{cllllllll}
\hline$\alpha_{1} \mathrm{~m}_{1}$ & $\alpha_{2} \mathrm{~m}_{2}$ & $\alpha_{3} \mathrm{~m}_{3}$ & $\beta_{1} \mathrm{~m}_{1}$ & $\beta_{2} \mathrm{~m}_{2}$ & $\beta_{3} \mathrm{~m}_{3}$ & $\gamma_{1} \mathrm{~m}_{1}$ & $\gamma_{2} \mathrm{~m}_{2}$ & $\gamma_{3} \mathrm{~m}_{3}$ \\
\hline-0.0097 & 0.0443 & -0.0681 & -0.0562 & -0.0379 & 0.0843 & 0.0957 & -0.0490 & -0.0462 \\
-0.0286 & 0.1269 & -0.0892 & 0.0070 & -0.0186 & -0.0051 & -0.0420 & -0.0154 & 0.0563 \\
1590 & 0.3329 & 0.0560 & 0.0854 & -0.1720 & -0.0529 & 0.0093 & -0.3455 & 0.0833 \\
0.0067 & 0.0457 & -0.0574 & -0.0915 & 0.0022 & 0.0437 & 0.0518 & -0.0543 & 0.0018 \\
0.0639 & -0.0495 & -0.0179 & -0.1287 & -0.0359 & 0.2037 & 0.1847 & 0.2054 & -0.6258 \\
-0.0270 & 0.0084 & 0.0107 & 0.0167 & -0.0217 & -0.0052 & -0.0092 & 0.0249 & -0.0263 \\
0.0058 & -0.0389 & 0.0374 & -0.0858 & 0.0709 & -0.0455 & 0.0036 & -0.0005 & -0.0208 \\
-0.0468 & -0.0233 & 0.0642 & -0.0423 & 0.0146 & 0.0216 & 0.1851 & 0.0165 & -0.2354 \\
-0.0703 & 0.0775 & -0.0308 & 0.0360 & -0.0340 & -0.0085 & 0.0058 & -0.0687 & 0.0556 \\
-0.1011 & 1.0212 & 0.0576 & 0.0345 & -0.6023 & 0.0175 & 0.1723 & -1.6476 & -0.1850 \\
\hline
\end{tabular}

Table 6: Results of fractional masses of ingredients to be added in the system

\begin{tabular}{|c|c|c|}
\hline$\alpha_{t} \underline{m}_{=} \alpha_{1} m_{1}+\alpha_{2} m_{2}+\alpha_{3} m_{3}+M_{\text {oil }}$ & $\beta_{\mathrm{m}}=\beta_{1} \mathrm{~m}_{1}+\beta_{2} \mathrm{~m}_{2}+\beta_{3} \mathrm{~m}_{3}+\mathrm{M}_{\mathrm{ash}}$ & $\gamma_{\mathrm{m}}=\gamma_{1} \mathrm{~m}_{1}+\gamma_{2} \mathrm{~m}_{2}+\gamma_{3} \mathrm{~m}_{3}+\mathrm{M}_{\text {water }}$ \\
\hline 2.9665 & 1.9902 & 7.0005 \\
\hline 12.0091 & 0.9833 & 4.9981 \\
\hline 8.2299 & 9.8605 & 2.7471 \\
\hline 9.9950 & 0.9544 & 2.9993 \\
\hline 14.9965 & 13.0391 & 12.7643 \\
\hline 4.9921 & 10.9898 & 7.9894 \\
\hline 2.0043 & 7.9396 & 4.9823 \\
\hline 11.9941 & 8.9937 & 14.9662 \\
\hline 5.9764 & 12.9935 & 6.9927 \\
\hline 9.9777 & 11.4497 & 4.3397 \\
\hline
\end{tabular}


Table 7: Random numbers for estimated time

\begin{tabular}{ccccccccccc}
\hline Extraction & 17 & 4 & 13 & 2 & 9 & 12 & 8 & 12 & 14 & 20 \\
\hline Burning & 19 & 16 & 8 & 14 & 2 & 11 & 12 & 18 & 3 & 4 \\
Mixing & 3 & 7 & 17 & 1 & 12 & 18 & 19 & 7 & 15 & 6 \\
Leaching & 19 & 11 & 11 & 2 & 10 & 6 & 14 & 9 & 3 & 8 \\
Boiling & 13 & 4 & 8 & 11 & 14 & 7 & 12 & 2 & 3 & 2 \\
Cooking & 2 & 13 & 19 & 2 & 14 & 3 & 17 & 4 & 13 & 14 \\
Adding & 6 & 6 & 18 & 17 & 13 & 19 & 18 & 14 & 7 & 9 \\
Cooling & 11 & 14 & 12 & 17 & 11 & 13 & 20 & 7 & 14 & 20 \\
\hline
\end{tabular}

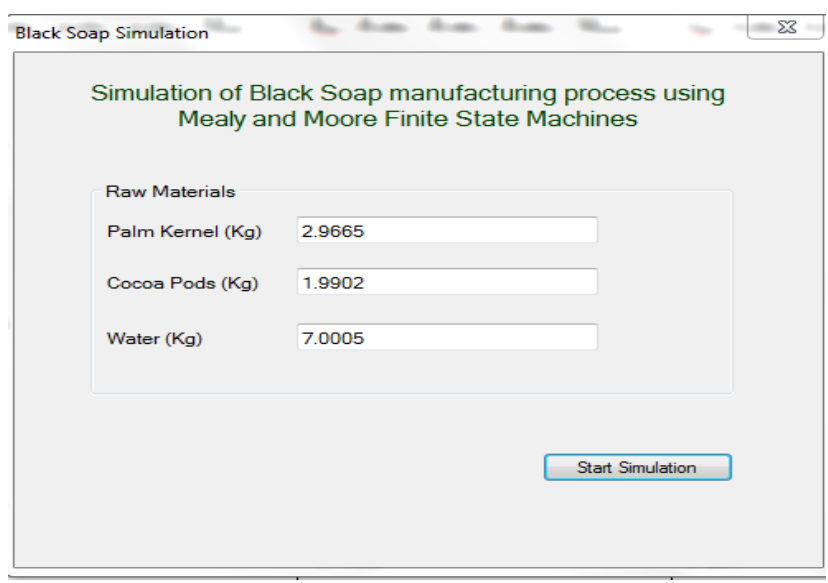

Figure 4(a): Inputting the Fractional Mass of Ingredients

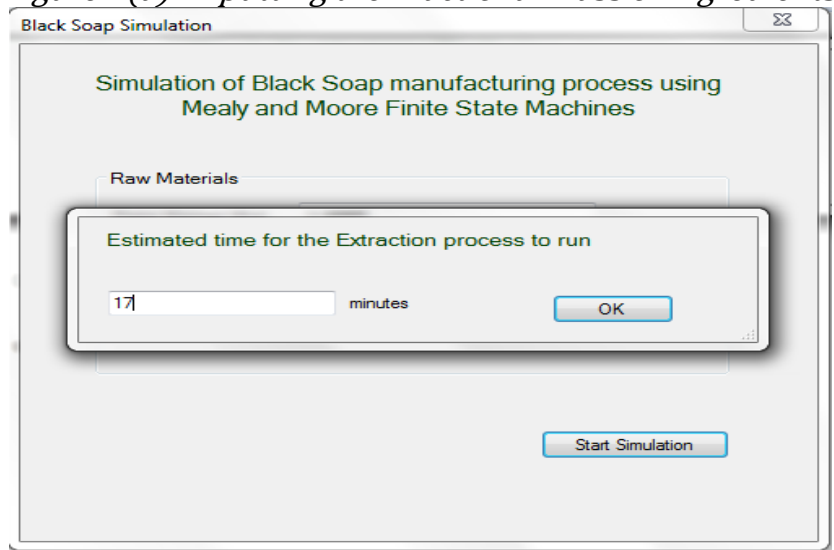

Figure 4(b): Estimated Time for the Extraction Process

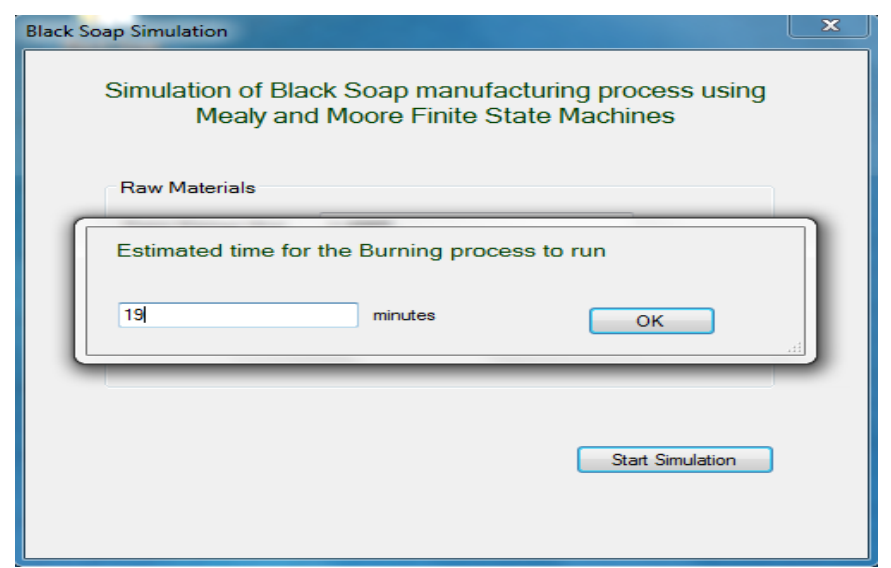

Figure 4(c): Estimated Time for Burning Process

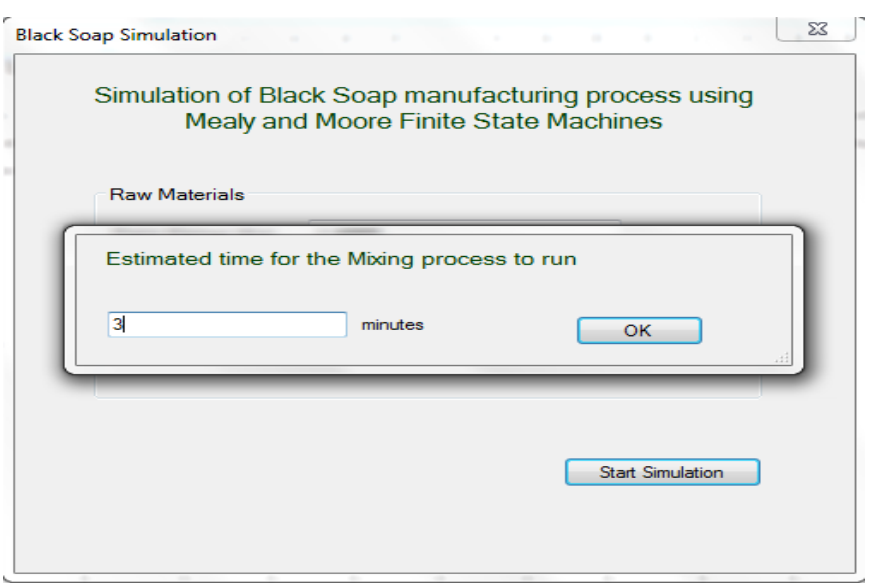

Figure 4(d): Estimated Time for Mixing Process

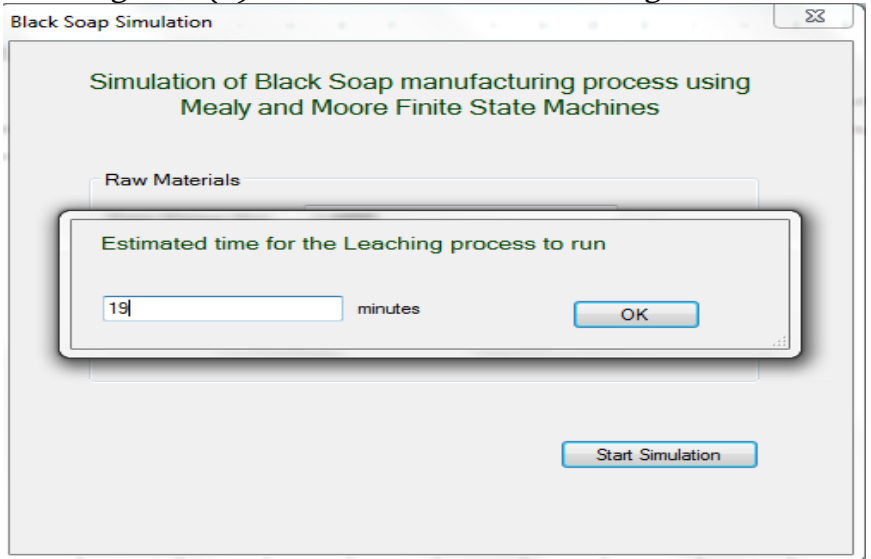

Figure 4(e): Estimated Time for Leaching Process

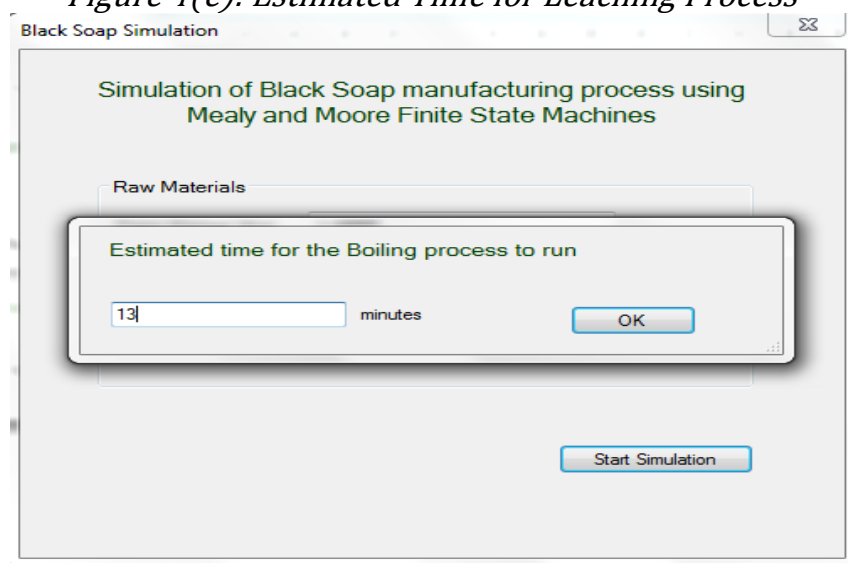

Figure 4(f): Estimated Time for Boiling Process 


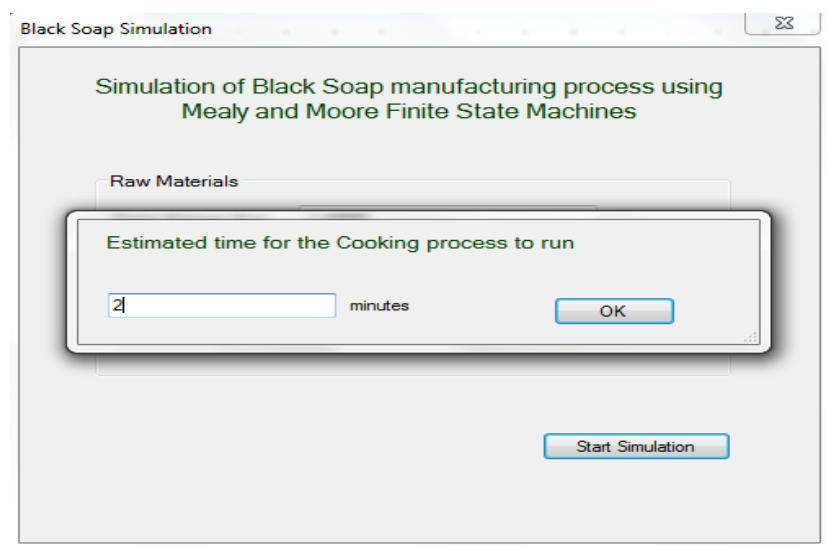

Figure 4(g): Estimated Time for Cooking Process

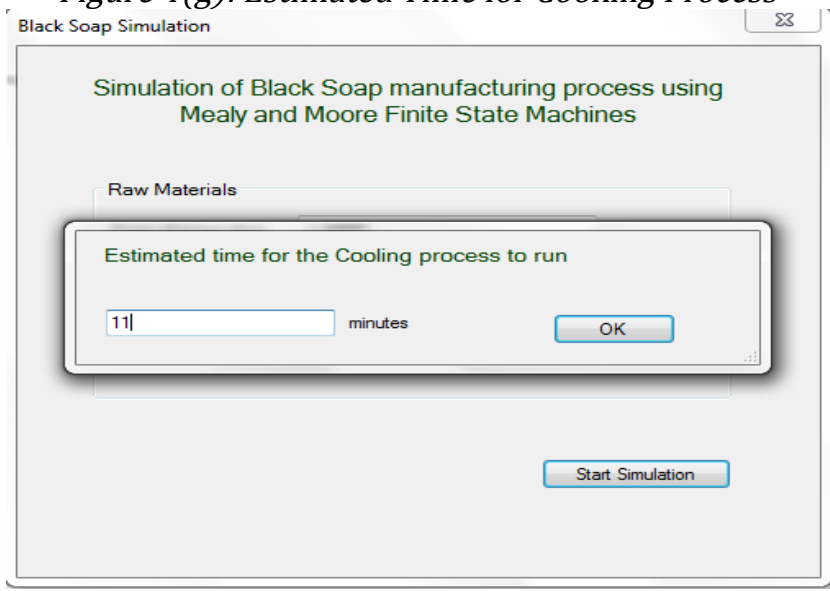

Figure 4(i): Estimated Time for Cooling Process

Table 8: Summary of execution times for Moore and Mealy Machines

\begin{tabular}{|c|c|c|c|}
\hline Runs & Moore Machine & Mealy Machine & $\begin{array}{c}\text { Quantity of } \\
\text { Soap Produced }\end{array}$ \\
\hline 1st Run & $1 \mathrm{hr} 30 \mathrm{mins} 0$ secs & $1 \mathrm{hr} 3$ mins 52 secs & $4.07 \mathrm{Kg}$ \\
\hline $2^{\text {nd }}$ Run & $1 \mathrm{hr} 15 \mathrm{mins} 0 \mathrm{sec}$ & Ohr 59mins 7secs & $7.64 \mathrm{Kg}$ \\
\hline $3^{\text {rd }}$ Run & $1 \mathrm{hr} 46 \mathrm{mins} 0 \mathrm{sec}$ & $1 \mathrm{hr} 14 \mathrm{mins} 1 \mathrm{sec}$ & $6.25 \mathrm{Kg}$ \\
\hline $4^{\text {th }}$ Run & $1 \mathrm{hr} 6 \mathrm{mins} 0 \mathrm{sec}$ & Ohr 45 mins 15 secs & $5.99 \mathrm{Kg}$ \\
\hline $5^{\text {th }}$ Run & $1 \mathrm{hrs} 25 \mathrm{mins}$ 0secs & $1 \mathrm{hr} 8$ mins 45 secs & $13.34 \mathrm{Kg}$ \\
\hline $6^{\text {th }}$ Run & $1 \mathrm{hr} 29 \mathrm{mins} 0 \mathrm{sec}$ & $1 \mathrm{hr} 0 \mathrm{mins} 5$ secs & $6.6 \mathrm{Kg}$ \\
\hline $7^{\text {th }}$ Run & $2 \mathrm{hrs} 10 \mathrm{mins} 0 \mathrm{sec}$ & $1 \mathrm{hr} 27$ mins 49 secs & $3.73 \mathrm{Kg}$ \\
\hline $8^{\text {th }}$ Run & $1 \mathrm{hr} 3 \mathrm{mins} 0 \mathrm{sec}$ & Ohr 49mins $1 \mathrm{sec}$ & $12.08 \mathrm{Kg}$ \\
\hline $9^{\text {th }}$ Run & $1 \mathrm{hr} 12 \mathrm{mins} 0 \mathrm{sec}$ & Ohr 51mins 5secs & $7.01 \mathrm{Kg}$ \\
\hline $10^{\text {th }}$ Run & $1 \mathrm{hr} 23 \mathrm{mins} 0 \mathrm{sec}$ & $1 \mathrm{hr} 1 \mathrm{mins} 21 \mathrm{secs}$ & $7.85 \mathrm{Kg}$ \\
\hline
\end{tabular}

\section{CONCLUSION}

The production of the popular ABS is still done manually which demands hours of stirring by hand amongst other manual tasks and this implies that the production involves strenuous human efforts. The mixing of ingredients is done with a stick or wooden ladle and this requires a lot of energy and timed input by the soap producer. Most times, the final product is usually not uniformly mixed due to fatigue usually suffered by the operator. This paper developed computational models for the concept black soap making process using Moore and Mealy Machines. These machines were compared in order to determine the most effective machine for the

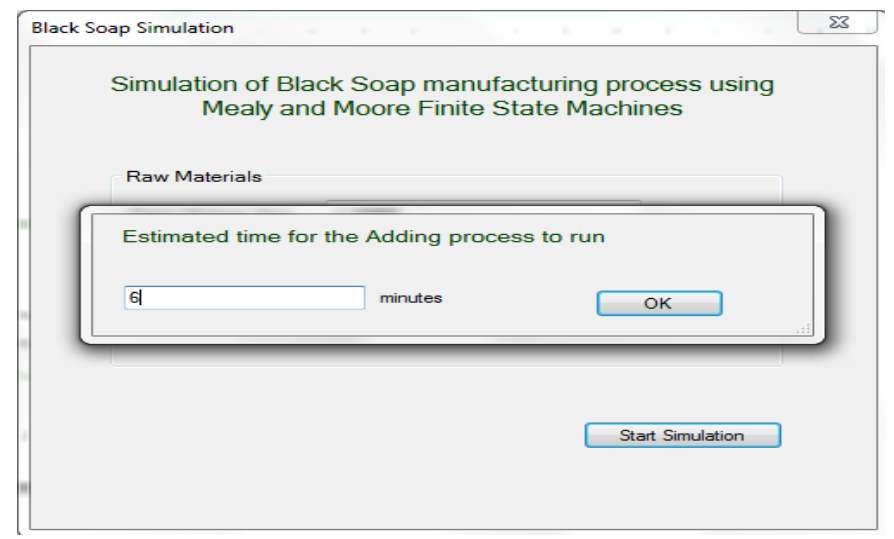

Figure 4(h): Estimated Time for Adding Process

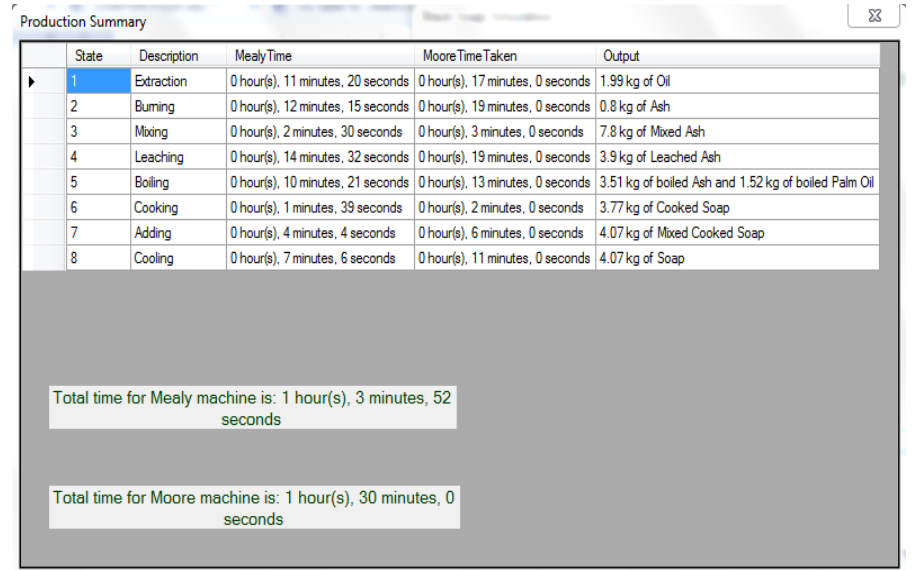

Figure 4(j): Production Summary for the First Run

process. A mathematical model was generated using input-output methodology to represent this process. The models input dataset were generated using pseudo random numbers from MATLAB. The activities in these models were simulated using $C \#$ programming language. Results showed that the Mealy Machine to be more efficient than the Moore Machine. This is because, using asynchronous logic, Mealy Machine produces outputs faster than the Moore Machine which is synchronous in nature thereby, increasing speed of production and cost, making it a more economical option. The study will improve decision making and reduce both the time and cost required to complete the production process since the quantity to produce a mass of soap can be derived at a given time.

\section{REFERENCES}

[1.] Monga, A. and Singh, B. Finite State Machine based Vending Machine Controller with Auto-Billing Features. International Journal of VLSI design \& Communication Systems (VLSICS) Vol.3, Number 2, pp. 19 - 28. 2012.

[2.] Ajao, K. R., Mustapha K., Mahamood, M. R and Iyanda M. O. Design and Development of a Pedal-powered 
Soap Mixer. New York Science Journal. Vol. 3 Number 1, pp.6 - 9. 2010.

[3.] Taiwo, O. E and. Osinowo, F. A. O. Evaluation of Various agro-wastes for traditional soap production. Bioresource Technology. Vol. 79, Issue 1, pp. 95 - 97. 2001.

[4.] Underwood, K."What is Black Soap?" http//www.treehugger.com/style/what-is-blacksoap-.html, 2008, Accessed 19 December 2016.

[5.] Jonathan, S. G., Efunshile, A. M. Olawuyi, O. J. Babalola, B. J. Efuntoye, M. O., and Dixon, D. O. Antifungal potentials of indigenous black soap commonly used in Ibadan, Nigeria. Academia Arena, Vol. 5, Number 7, pp. 50 - 55. 2013.

[6.] Ibrahim, Z., Ibrahim, A. A., and Garba, A. Modeling of Sokoto Cement Production Process Using A Finite Automata Scheme: An Analysis of The Detailed Model. International Journal of Computational Engineering Research, Vol. 4, Issue 5, pp.68 - 74. 2014,

[7.] Varkey, M. R. and Sunny, J. M. Design and Implementation of Multi Select Smart Vending Machine. International Journal of Computer Networks and Wireless Communications (IJCNWC), Vol.4, Number1, pp.42 - 452014.

[8.] Sitaula, C. and Ojha, Y. R. Semantic Sentence Similarity Using Finite State Machine. Intelligent Information Management Vol. 5, pp. 171-174. 2013.
[9.] Verma, D. and Karambir, B. Component testing using finite automata. Indian Journal of Computer Science and Engineering, Vol. 3 Number.5, pp.658 - 666. 2012.

[10] Klimovich, A. S and Solov'ev, V. V. Transformation of a mealy finite-state machine into a moore finitestate machine by splitting internal states. Journal of Computer and Systems Sciences International. Vol. 49, Issue 6, pp.900 - 908. 2010,

[11] Zainuddin, F., Ali, N. M., Sidek, R. M. Romli, A., Talib, N., and Ibrahim, M. I. "Conceptual modeling for simulation: Steaming frozen food processing in vending machine", 2nd IEEE International Conference on Computer Science and Information Technology, Beijing: IEEE, August 8 - 11, pp.145 1492009.

[12] Gurov, V. S., Mazin, M. A., Narvsky, A. S., Shalyto, A. A. "UniMod: Method and Tool for Development of Reactive Object-Oriented Programs with Explicit States Emphasis", Proceedings of St. Petersburg IEEE Chapters International Conference "110 Anniversary of Radio Invention”. SPb ETU “LETI”. Vol. 2, pp. 106110. 2005

[13] Wagner, T., Wolstenholme, P., Schmuki, R., and Wagner, F. Modeling Software with Finite State Machines: A Practical Approach. Taylor \& Francis Ltd. London, United Kingdom, 2006. 